\title{
Retinoic Acid
}

\author{
INHIBITION OF THE CLONAL GROWTH \\ OF HUMAN MYELOID LEUKEMIA CELLS
}

\author{
Dan Douer and H. Phillip Koeffler, Division of Hematology/Oncology, \\ Department of Medicine, University of California School of Medicine, \\ Los Angeles, California 90024
}

A B S T R A C T Vitamin A and its analogues (retinoids) affect normal and malignant hematopoietic cells. We examined the effect of retinoids on the clonal growth in vitro of myeloid leukemia cells. Retinoic acid inhibited the clonal growth of the KG-1, acute myeloblastic leukemia, and the HL-60, acute promyelocytic leukemia, human cell lines. The KG-1 cells were extremely sensitive to retinoic acid, with $50 \%$ of the colonies inhibited by 2.4-nM concentrations of the drug. A 50\% growth inhibition of HL-60 was achieved by $25 \mathrm{nM}$ retinoic acid. Complete inhibition of growth of both leukemia cell lines was seen with $1 \mu \mathrm{M}$ retinoic acid. Exposure of KG-1 cells to retinoic acid for only 3-5 $d$ was sufficient to inhibit all clonal growth. The all-trans and 13-cis forms of retinoic acid were equally effective in inhibiting proliferation. Retinal, retinyl acetate, and retinol (vitamin A) were less potent inhibitors. Clonal growth of the human K562 and mouse M-1 myeloid leukemic cell lines was not affected by $10 \mu \mathrm{M}$ retinoic acid. Retinoic acid also inhibited the clonal growth of leukemia cells from five of seven patients with acute myeloid leukemia. Retinoic acid at concentrations of $5 \mathrm{nM}$ to $0.3 \mu \mathrm{M}$ inhibited $50 \%$ clonal growth, and $1 \mu \mathrm{M}$ retinoic acid inhibited $64-98 \%$ of the leukemic colonies. The inhibition of clonal growth of KG-1 and HL-60 cell lines and of leukemic cells from two patients was not associated with the presence of a specific cytoplasmic retinoic acid-binding protein. Our study suggests that retinoic acid may prove to be effective in the treatment of human myeloid leukemia.

\section{INTRODUCTION}

Vitamin A, its metabolites, and its analogues (retinoids) participate in the normal differentiation of epithelial

H. P. Koeffler is a scholar of the American Leukemia Society.

Received for publication 26 August 1981 and in revised form 5 October 1981. tissue $(1,2)$. Retinoids inhibit carcinogenesis in a variety of animal models $(2,3)$, suppress in vitro malignant transformation of certain cell lines $(4,5)$, and inhibit the growth of several tumor cell lines (6-9). Retinoids induce differentiation of mouse embryonal carcinoma cell lines (10). The recent discovery of a specific cytoplasmic retinoic acid-binding protein $(\mathrm{cRABP})^{1}$ in various tissues has led to the hypothesis that retinoids may bind to cRABP, be transported to the nucleus, and modify gene expression (8). Recent evidence suggests that retinoids are involved in growth and differentiation of hematopoietic cells. We have shown that retinoic acid at a concentration of $0.1 \mu \mathrm{M}$ can enhance clonal growth of normal human myeloid stem cells (11). Breitman et al. $(12,13)$ reported that low concentrations of retinoic acid induced the human promyelocytic leukemia cell line (HL-60) and cells from patients with acute promyelocytic leukemia to differentiate to morphologically and functionally mature granulocytes. This effect was limited to the promyelocytic type of myeloid leukemia, because retinoic acid did not induce differentiation of other subgroups of acute myeloid leukemia.

We studied the effect of retinoids on the clonal growth in soft gel culture of cells from three human acute myeloid leukemia (AML) cell lines, one mouse AML cell line, and leukemic cells freshly obtained from patients with myeloid leukemia. The colony formation assay provides a sensitive method for the study of the clonal proliferation of hematopoietic stem cells in the presence of chemically defined agents (14). In the present study we found that clonal growth of a number of myeloid leukemic cells is inhibited by retinoids. Inhibition of growth was not mediated by a cytoplasmic retinoic acid-binding protein.

\footnotetext{
${ }^{1}$ Abbreviations used in this paper: AML, acute myeloid leukemia; cRABP, cytoplasmic retinoic acid-binding protein; CSF, colony-stimulating factors; PBS, phosphate-buffered saline.
} 


\section{METHODS}

Cells. Three human AML cell lines, KG-1, HL-60, and K562 have been established (15). The KG-1 cell line was derived from a patient with erythroleukemia. The KG-1 cells are at the myeloblast stage of differentiation and retain the morphological and cytochemical characteristics of AML cells (16). The HL-60 cell line was derived from a patient with promyelocytic leukemia and the cells are predominantly at the promyelocytic stage of differentiation (17). The K562 cells were established from the pleural fluid of a patient with chronic myeloid leukemia in blastic crisis (18) and are composed of undifferentiated blast cells. The $M-1$ is a mouse AML cell line established from a spontaneous murine myeloid leukemia (19). All cells were maintained in continuous suspension culture in $\mathrm{T}$ flasks (Lux Scientific Corp., Newbury Park, Calif.) with alpha modified minimum essential medium (Flow Laboratories, Inc., Rockville, Md.), 20\% fetal calf serum (Gibco Laboratories, Grand Island Biological Co., Grand Island, N. Y.), penicillin, and streptomycin. The cells were grown in a humidified incubator with $5 \% \mathrm{CO}_{2}$ at $37^{\circ} \mathrm{C}$ and were refed twice weekly. Experiments were performed on cells that were in their logarithmic growth phase (2-3 d after subculturing in fresh medium).

Leukemic cells were obtained from the peripheral blood or bone marrow of four patients with AML, one patient with acute myelomonocytic leukemia and two patients with chronic myelocytic leukemia in myeloid blast crisis. We also classified their leukemic type according to the FrenchAmerican-British classification for leukemia (20) as follows: M1, acute myeloid leukemia having minimal evidence of differentiation along the granulocytic pathway; M2, clear evidence of maturation to granulocytic pathway; M3, promyelocytic leukemia; M4, myelomonocytic leukemia. Heparinized samples of blood or bone marrow were taken only from patients with high leukemia cell counts. Cells were isolated by Ficoll-Hypaque centrifugation, and the interphase mononuclear cells were harvested and washed twice in medium. The final cell suspension contained $\geq 90 \%$ leukemic cells as judged by morphology of Wright-stained cytocentrifuge preparations.

Retinoids. All-trans-retinoic acid, retinol, retinyl acetate, retinal (Sigma Chemical Co., St. Louis, Mo.) and 13-cisretinoic acid (a gift from Dr. B. Pawson, Hoffmann-La Roche, Inc., Nutley, N. J.) were stored at $-20^{\circ} \mathrm{C}$. Stock solutions of $10 \mathrm{mM}$ retinoids were prepared in $100 \%$ ethanol and stored at $-20^{\circ} \mathrm{C}$ for no longer than 1 wk. Dilutions of the stock were made in ethanol to concentrations varying from $1 \mathrm{mM}$ to $1 \mathrm{nM}$. Retinoids were diluted before their use in phosphate-buffered saline (PBS) to the appropriate concentration so that the final concentration of ethanol in the cultures was $0.1 \%$. All experiments were performed in subdued light, and tubes containing retinoids were covered with aluminum foil.

Colony formation in agar. Cells from the cell lines were suspended in alpha medium, $15 \%$ fetal calf serum, penicillin, streptomycin, and $0.3 \%$ agar and plated in $1-\mathrm{ml}$ portions in a $35-\mathrm{mm}$ petri dish containing $0.1 \mathrm{ml}$ of retinoid solution. Control dishes contained $0.1 \mathrm{ml}$ of PBS with a final concentration of $0.1 \%$ ethanol. This concentration of ethanol did not alter the colony formation when compared with cultures without ethanol.

The KG-1 cell line requires colony-stimulating factor (CSF) for its growth. The CSF was conditioned medium from a human T-lymphocyte cell line known as Mo (21). It was added to the cultures at an optimal growth-stimulating concentration (1.5\%). The HL-60, K562, and M-1 cells form colonies without CSF. The same lot of CSF- and Mo-conditioned medium was used for all experiments. The cloning efficiency of each cell type varies, and to have a convenient number of colonies in each plate, the KG-1 cells were plated at $4 \times 10^{3}, \mathrm{HL}-60$ at $1.5 \times 10^{3}, \mathrm{~K} 562$ at $1 \times 10^{3}$, and M-1 at $4 \times 10^{3}$ cells $/$ dish. The cloning efficiency of the KG-1 cell in the presence of CSF was $4 \%$. The cloning efficiency of HL-60, K562, and M-1 was 32,79 , and $18 \%$, respectively. These cells were plated without CSF.

Leukemic cells freshly obtained from patients were grown by the two-layer agar technique. The CSF was provided by underlayers prepared with $1 \times 10^{6}$ normal human peripheral blood leukocytes in alpha medium, fetal calf serum, and $0.5 \%$ agar together with $0.1 \mathrm{ml}$ retinoic acid solution. We have found that fresh leukemic cells form colonies more readily with leukocyte underlayers than with Mo-conditioned medium. A total of $2 \times 10^{5}$ leukemic cells $/ \mathrm{ml}$ were seeded as overlayers by a method similar to that used for the cell lines. The culture dishes were incubated at $37^{\circ} \mathrm{C}$ in a humidified atmosphere containing $5 \% \mathrm{CO}_{2}$ for $10-14 \mathrm{~d}$. Colonies ( 240 cells) and clusters (10-40 cells) were scored with the aid of an inverted microscope. In each experiment three to four dishes per point were seeded.

Assay for cy toplasmic retinoic acid-binding protein. The KG-1 and HL-60 cells were grown in suspension cultures as described above and washed three times with PBS. We also studied the cells from the 3T6 mouse fibroblast line as a positive control because they have cRABP (8). These cells were grown in a monolayer culture in Dulbecco's modification of Eagle's medium and $10 \%$ fetal calf serum. They were collected with $0.25 \%$ trypsin and washed three times with PBS. Each of the cell types $\left(3 \times 10^{8}-5 \times 10^{8}\right.$ cells) was pelleted and homogenized by sonication for $30 \mathrm{~s}$ in $\mathbf{5 0}$ $\mathrm{nM}$ of Tris-HCl buffer, $\mathrm{pH}$ 7.5. The homogenate was centrifuged for $10 \mathrm{~min}$ at $31,000 \mathrm{~g}$, and the suspension was spun again for $1 \mathrm{~h}$ at $105,000 \mathrm{~g}$. The protein concentration in the cytosol was between 11 and $17 \mathrm{mg} / \mathrm{ml}$. The supernatant cytosol was tested for the presence of $\mathrm{cRABP}$ according to the method of Ong and Chytil (22). In brief, the cytosol was incubated with $50 \mathrm{nM}\left[{ }^{3} \mathrm{H}\right]$ retinoic acid $(40 \mathrm{Ci} / \mathrm{mmol}$, Hoffmann-La Roche, Inc.) for $5 \mathrm{~h}$ at $4^{\circ} \mathrm{C}$ in subdued light. Separate cytosol samples were incubated with $50 \mathrm{nM}\left[{ }^{3} \mathrm{H}\right]$ retinoic acid plus $200 \mathrm{M}$ excess unlabeled retinoic acid to measure nonspecific binding. The cytosol samples were mixed for 5 min with a $1 \%$ charcoal-dextran suspension to absorb the unbound retinoic acid. The charcoal-coated dextran was removed by centrifugation, and $0.2 \mathrm{ml}$ of the cytosol supernatant was applied on the top of a 5-20\% sucrose gradient containing $10 \mathrm{mM}$ Tris- $\mathrm{HCl}, \mathrm{pH} 7.5,1 \mathrm{mM}$ disodium EDTA, $10 \mathrm{mM} \mathrm{KCl}$, and $10 \mathrm{mM}$ monothioglycerol. The sucrose gradients were spun at $220,000 \mathrm{~g}$ for $20 \mathrm{~h}$ at $4^{\circ} \mathrm{C}$. Fractions of $0.250 \mathrm{ml}$ were collected and counted for tritium with a liquid scintillation spectrophotometer (model LS-330, Beckman Instruments, Inc., Fullerton, Calif.). $\left[{ }^{14} \mathrm{C}\right]$ Bovine serum albumin (4.6S) and $\left[{ }^{14} \mathrm{C}\right]$ cytochrome $c(1.71 \mathrm{~S}$, New England Nuclear, Boston, Mass.) were used as external markers.

\section{RESULTS}

Effect of retinoic acid on clonal growth of cells from myeloid leukemia lines. The ability of various concentrations of retinoic acid to inhibit colony formation of three human and one mouse AML cell lines is shown in Fig. 1. The human KG-1 and HL-60 myeloid cell lines were markedly inhibited. The KG-1 


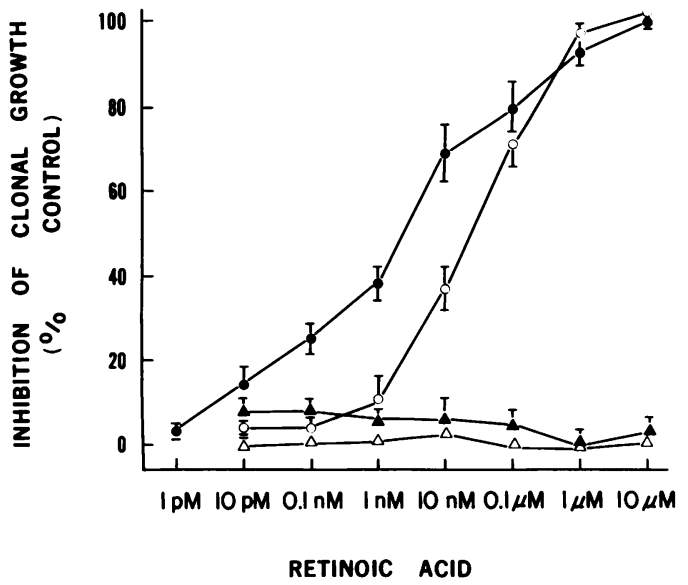

Figure 1 Retinoic acid dose-response curves of clonal growth inhibition of KG-1 (O), HL-60 (O), K562 (A), and M-1 $(\Delta)$ myeloid leukemia cell lines. The results are expressed as the percentage of inhibition of colony growth in plates containing retinoic acid as compared with the number of colonies in control dishes without retinoic acid. Each point represents the mean of three to four experiments carried out with quadruplicate plates.

cells were the most sensitive to the inhibitory effect of retinoic acid. Clonal growth of the KG-1 cells was slightly inhibited at a retinoic acid concentration of $10 \mathrm{pM}$. A $50 \%$ inhibition of clonal growth was observed with $2.4 \mathrm{nM}$ retinoic acid. The $50 \%$ inhibition of the HL-60 cells was achieved with $25 \mathrm{nM}$ retinoic acid. The clonal growth of the myeloid leukemia cell line $\mathrm{K} 562$, and the murine AML cell line, M-1, was not inhibited by retinoic acid at concentrations up to 10 $\mu \mathrm{M}$. Clonal growth of normal human myeloid progenitor cells is inhibited by $10 \mu \mathrm{M}$ retinoic acid (11).

We determined how long KG-1 cells must be exposed to retinoic acid for clonal proliferation to be inhibited. The KG-1 cells $\left(1.5 \times 10^{5}\right)$ were suspended in liquid culture containing $1 \mu \mathrm{M}$ retinoic acid, alpha medium, $15 \%$ fetal calf serum, and $10 \mu \mathrm{l} / \mathrm{ml}$ Mo-conditioned medium. Control cells were grown in liquid culture without retinoic acid. The cells were harvested and counted after 1,8 , and $24 \mathrm{~h}$ and then at daily intervals. Cell growth in liquid culture was slower in the presence of retinoic acid as compared with controls (data not shown). However, no difference in viability was noted between cells from the retinoic acid-containing cultures and control cultures as judged by trypan blue viability ( $85 \%$ or more viable cells after $5 \mathrm{~d}$ in liquid culture). The cells were washed three times in alpha medium, counted, and plated at 4 $\times 10^{3}$ cells/dish in agar with Mo-conditioned medium but without retinoic acid. After $48 \mathrm{~h}$ in liquid culture with retinoic acid the KG-1 cells had a reduced clonal growth as compared with cells from control cultures (Fig. 2). The KG-1 cells rarely formed colonies after

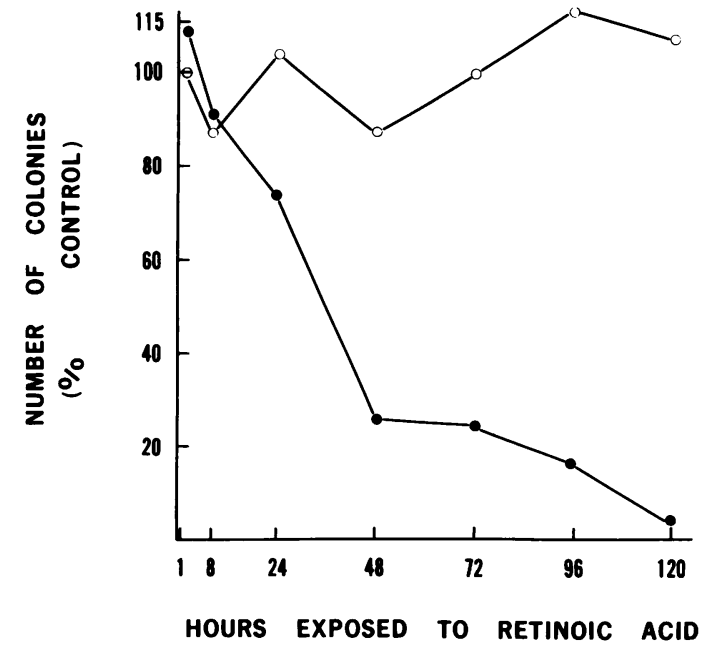

Figure 2 Effect of exposure time of retinoic acid on the inhibition of KG-1 clonal growth. Cells were incubated in liquid culture with either $0.1 \%$ ethanol in PBS $(O$, control) or $1 \mu \mathrm{M}$ retinoic acid ( $)$. After 1,8 , and $24 \mathrm{~h}$ and then at daily intervals the cells were washed and assayed for colony formation in agar not containing retinoic acid. The number of colonies that grew from cells incubated for $1 \mathrm{~h}$ without retinoic acid was 158/dish, and this was defined as $100 \%$ growth. All other results were expressed as percentage of colonies that grew compared with the control cells incubated without retinoic acid for $1 \mathrm{~h}$.

exposure to $1 \mu \mathrm{M}$ retinoic acid in liquid culture for $\geq 5 \mathrm{~d}$.

Effect of various retinoids on KG-1 clonal growth. The effect of various analogues of vitamin A on KG1 clonal growth was examined (Fig. 3). We found that 13-cis-retinoic acid was as effective as all-trans-retinoic acid in inhibiting the growth of the KG-1 cells.

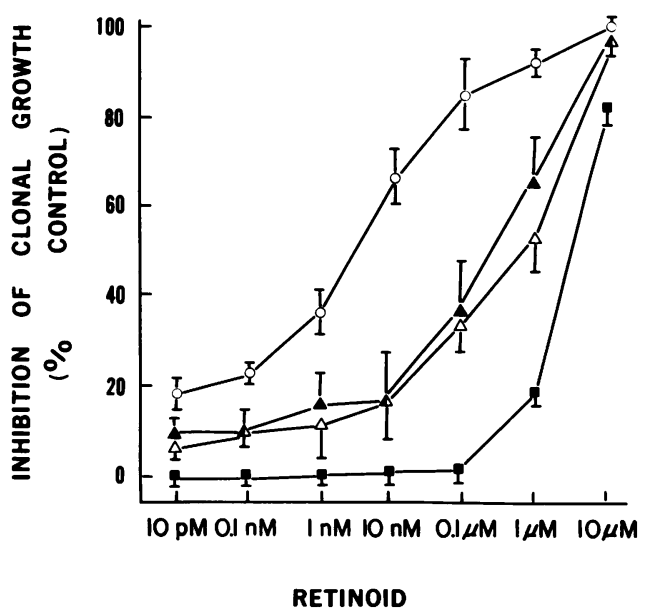

FIGURE 3 Dose-response curves of KG-1 clonal growth inhibition by four vitamin $A$ analogues (retinoids): 13-cisretinoic acid $(O)$, retinal $(\Delta)$, retinyl acetate $(\Delta)$, and retinol $(\square)$. Results expressed as described in legend to Fig. 1. 
13-cis-retinoic acid at $3.2 \mathrm{nM}$ inhibited $50 \%$ of growth. Retinol and retinyl acetate were less potent and a 50\% inhibition was achieved at 0.2 and $0.7 \mu \mathrm{M}$, respectively. Retinol was the least effective; $19 \%$ inhibition was observed at $1 \mu \mathrm{M}$.

We studied whether the nearly inactive retinol could block the inhibitory effect of retinoic acid on KG-1 growth. The KG-1 cells were grown in agar with 2 nM-10 pM retinoic acid together with 50-10,000-fold excess retinol $(0.1 \mu \mathrm{M})$, and the colony number was examined. No difference was observed in the inhibitory effect of the various concentrations of retinoic acid in the presence of retinol compared with cultures containing retinoic acid alone.

Effect of retinoic acid on clonal growth of fresh myeloid leukemia cells from patients. Retinoic acid inhibited $\geq 50 \%$ of the clonal growth of leukemic cells from five of seven patients (Table I). Inhibition varied among the patients, and $50 \%$ inhibition of clonal growth was observed in the presence of $5 \mathrm{nM}$ to 0.3 $\mu \mathrm{M}$ retinoic acid (Table I, Fig. 4). In these five patients, $1 \mu \mathrm{M}$ retinoic acid inhibited the growth of $64-98 \%$ of the colonies and clusters (Fig. 4). Retinoic acid at a concentration of $10 \mu \mathrm{M}$ inhibited only $45 \%$ of leukemic cell clonal growth from patient 6 and did not affect the proliferation of cells from patient 7 (Fig. 4). In no instance did retinoic acid stimulate colony formation. Cells from patients $2,4,6$, and 7 were incubated in liquid culture with and without $1 \mu \mathrm{M}$ retinoic acid for $5 \mathrm{~d}$. No difference in morphology, as viewed by light microscopy, of Wright-stained cytocentrifuged preparations was observed in the cells cultured with retinoic acid as compared with cells cultured without retinoic acid (data not shown).

Absence of cRABP in myeloid leukemic cells. The cytosol of the $3 \mathrm{~T} 6$ cells binds $\left[{ }^{3} \mathrm{H}\right] \mathrm{retinoic}$ acid, demonstrating a single cRABP receptor peak sedimenting at the $2 \mathrm{~S}$ region of the sucrose density gradient (Fig. $5 \mathrm{~A})$. The binding of the cRABP is specific because nonradiolabeled retinoic acid competed for the binding sites.

Cytosols from the KG-1 and HL-60 cells and fresh human leukemic cells (numbers 2 and 3 ) were examined in a similar way and no binding of $\left[{ }^{3} \mathrm{H}\right]$ retinoic acid was detected (Fig. 5B-E).

A mixing experiment was performed to ensure that leukemic lysosomal enzymes were not degrading the cRABP when the cytosol was prepared. The cytosol from the KG-1 and HL-60 cells were each mixed with the $3 \mathrm{~T} 6$ cell cytosol in equal proportions and the mixture was examined for cRABP. The cytosol of the KG1 and of the HL- 60 cells did not affect the cRABP of the $3 \mathrm{~T} 6$ cells (Fig. 5F).

\section{DISCUSSION}

The data presented shows that retinoic acid inhibited the clonal growth of two human myeloid leukemia cell lines, KG-1 and HL-60. The KG-1 cell line was extremely sensitive to retinoic acid, and $50 \%$ of the col-

TABLE I

Concentration of Retinoic Acid That Inhibits $50 \%$ of Clonal Growth of Leukemic Cells Freshly Obtained from Myeloid Leukemia Patients

\begin{tabular}{llccr}
\hline $\begin{array}{c}\text { Patient } \\
\text { No. }\end{array}$ & $\begin{array}{c}\text { Leukemia } \\
\text { type }\end{array}$ & FAB & $\begin{array}{c}\text { Colonies plus } \\
\text { clusters in } \\
\text { control dishes }\end{array}$ & $\begin{array}{c}\text { Retinoic acid } \\
\text { concentration } \\
\text { inhibiting } 50 \% \text { of } \\
\text { clonal growtht }\end{array}$ \\
\hline & & & $\begin{array}{c}\text { No./2 } \times 10^{5} \\
\text { cells seeded }\end{array}$ & \\
1 & AML & M2 & 75 & $5.0 \mathrm{nM}$ \\
2 & AML & M2 & 693 & $12.6 \mathrm{nM}$ \\
3 & AML & M1 & 138 & $40.0 \mathrm{nM}$ \\
4 & CML-BC & - & 73 & $0.2 \mu \mathrm{M}$ \\
5 & CML-BC & - & 52 & $0.3 \mu \mathrm{M}$ \\
6 & AMMOL & M4 & 820 & $>10.0 \mu \mathrm{M}$ \\
7 & AML & M1 & 550 & $>10.0 \mu \mathrm{M}$ \\
\hline
\end{tabular}

FAB, French-American-British classification for leukemia.

CML-BC, chronic myeloid leukemia in myeloid blast crisis.

AMMOL, acute myelomonocytic leukemia.

- Control dishes grown in the absence of retinoic acid.

t The concentration of retinoic acid that inhibited $50 \%$ of the number of colonies and clusters in the control dishes. The results were obtained by interpolation from Fig. 4 . 


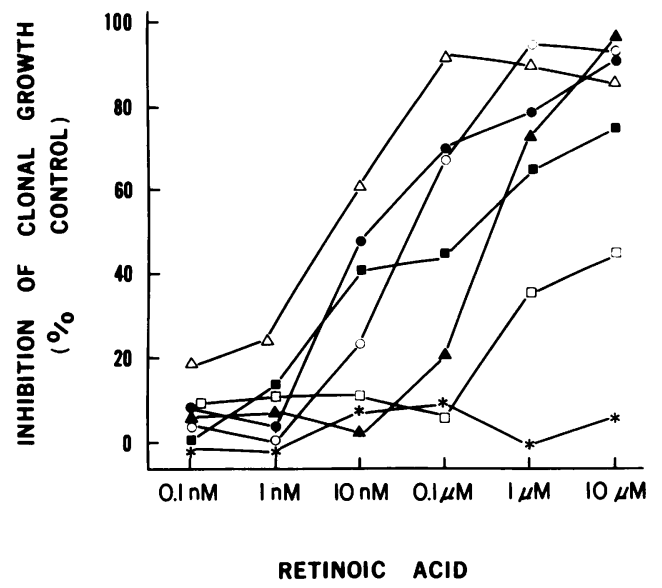

FIGURE 4 Retinoic acid dose-response curves of clonal growth inhibition of leukemic cells obtained from patients with myeloid leukemia. Results expressed as described in legend to Fig. 1. Patient numbers: $1(\Delta) ; 2(\Theta) ; 3(O) ; 4$

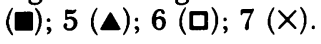

onies were inhibited by $2.4 \mathrm{nM}$ retinoic acid. Also, retinoic acid significantly inhibited the in vitro clonal growth of leukemic cells from five patients. Recently, Breitman et al. (12) have reported that retinoic acid can induce differentiation of leukemic cells blocked at the promyelocyte stage (M3) of differentiation but is unable to induce differentiation of myeloid leukemic cells that are arrested at other stages of differentiation. In contrast, we found in the patients studied that clonal growth of AML (M1 and M2) and acute myelomonocytic leukemia (M4) cells were inhibited by retinoic acid. Retinoic acid did not induce morphological, histochemical, or functional differentiation of the cells from the KG-1 cell line or from the patients (data not shown). In the patient studies, the inhibited colonies probably were not derived from normal hematopoietic stem cells. Studies with chromosomal markers have shown that the colonies developing in the soft gel colony assay from cells of leukemic patients are derived from the leukemic clone (23). Also, we (11) have shown that $10 \mathrm{nM}-1 \mu \mathrm{M}$ retinoic acid enhances normal human myeloid clonal proliferation.

We found that the clonal growth of the human blast cell line K562, the murine M-1 cells, and leukemic cells from two of seven patients was not inhibited by retinoic acid. The reason for the heterogeneity of response to retinoic acid is not clear at this time.

The acid forms of vitamin A, i.e., retinoic acid and its 13 -cis analogue, were the most potent retinoids in inhibiting the growth of the KG-1 cells. Other investigators have found that the acid forms of vitamin A have the greatest antitumor effect in several biological systems (6). The alcohol and aldehyde forms of vitamin
A (retinol and retinal, respectively) can be metabolically oxidized to retinoic acid. Retinoic acid or one of its metabolites may be the active substance in a variety of biological systems.

Lacroix and Lippman (9) have reported that the growth inhibition of retinoic acid on cells from human breast cancer cell lines is reversible after the removal of retinoic acid. We found that the inhibitory effect of retinoic acid on clonal growth of KG-1 cells was not reversible after its removal from the cells. The irreversibility may have been due to a cytotoxic effect. The mechanism of inhibition of leukemic growth by retinoic acid is not clear, but our data does suggest that the inhibition is probably more than a nonspecific toxic effect. Inhibition of KG-1, HL-60, and $70 \%$ of leukemic patient cells occurred at very low concentrations of retinoic acid. Furthermore, cellular viability in liquid culture of KG-1 and HL-60 cells was not reduced by prolonged exposure to $1 \mu \mathrm{M}$ retinoic acid. Likewise, the growth of the K562 and M-1 cells was not affected by $10 \mu \mathrm{M}$ of retinoic acid. We previously have shown that retinoic acid and other retinoids enhanced the CSF-stimulated clonal growth of normal myeloid progenitor cells (11). A concentration of 0.1 $\mu \mathrm{M}$ retinoic acid increased normal myeloid stem cell clonal proliferation approximately twofold. Inhibition of normal myeloid proliferation by retinoic acid occurred only at a very high concentration $(10 \mu \mathrm{M})$.

The mechanism of action of retinoids in various biological systems is unknown. A specific cRABP receptor has been identified in several normal and neoplastic tissues $(8,9,22,24)$, and it has been proposed that the biological effects of retinoic acid might be mediated by this receptor (8). Investigators $(25,26)$ have found that the ability of retinoids to bind to cRABP correlates with its biological activity in a variety of biological systems. Frequently, however, the sensitivity of the cells to growth inhibition by retinoic acid did not correlate with the level of $C R A B P$ in the cell (27). We demonstrate here that the clonal growth of two human myeloid leukemic cell lines and cells from two patients with AML was inhibited by low concentrations of retinoic acid, but the cells did not have detectable cRABP. Our studies add further support to the view presented by Lotan et al. (27) that modulation of tumor cell growth rate by retinoic acid is not necessarily mediated by cRABP. It may be possible that CRABP mediates other biological activities, such as induction of differentiation of certain tumor cell types. For example, cells from a murine embryonal cell carcinoma line that contains cRABP differentiate in response to retinoic acid, whereas two mutants of this cell line that lack the receptor have lost their abil- 

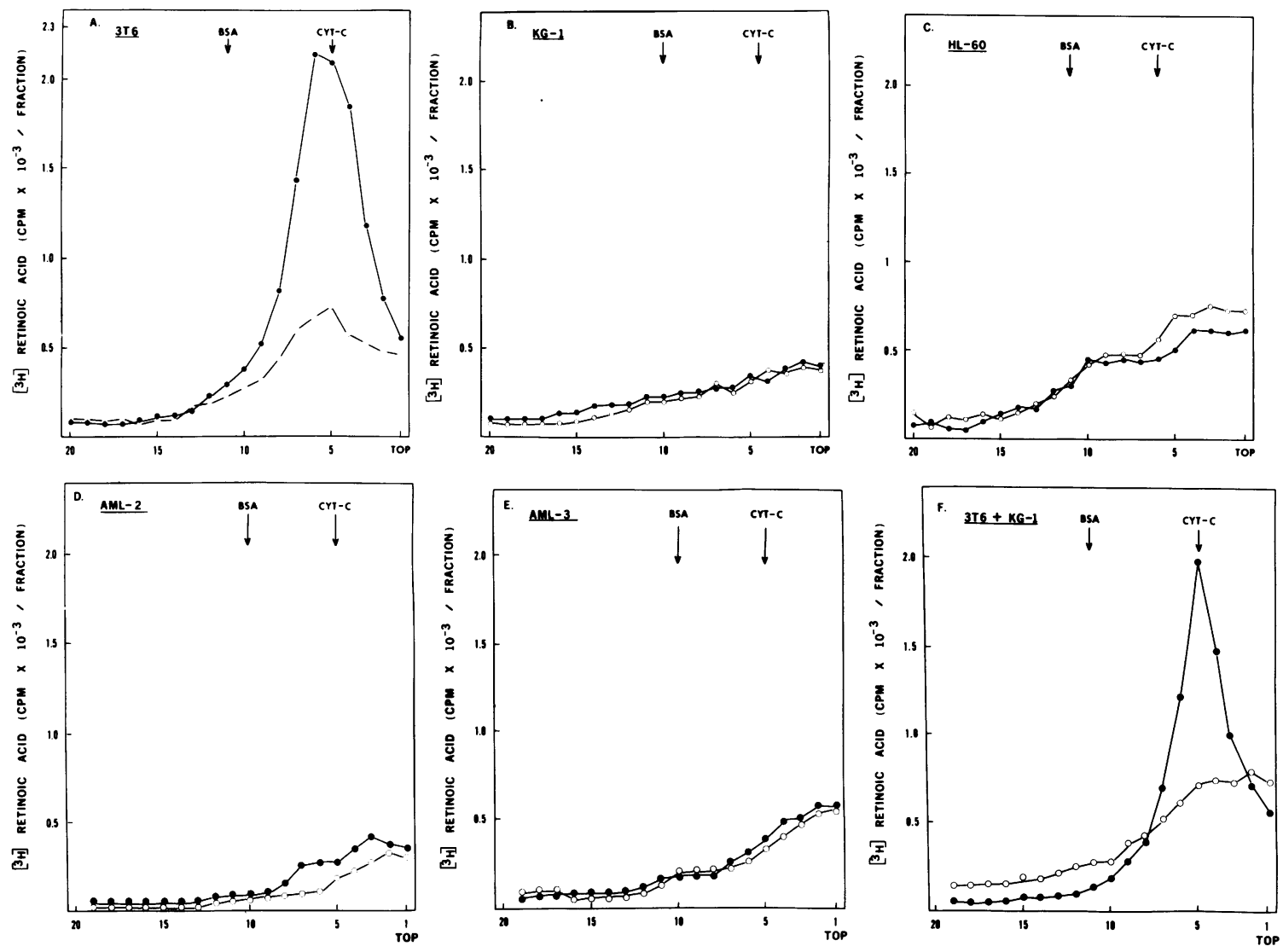

Figure 5 Sucrose gradient analysis of binding of $\left[{ }^{3} \mathrm{H}\right]$ retinoic acid to cytosol of $(A) 3 \mathrm{~T} 6$ cells, $(B)$ KG-1 cells, $(C)$ HL-60 cells, $(D)$ cells from patient $2,(E)$ cells from patient $3,(F)$ binding of $\left[{ }^{3} \mathrm{H}\right]$ retinoic acid to a 1:1 mixture of cytosols from $3 \mathrm{~T} 6$ cells and KG-1 cells. Cytosols were incubated with $50 \mathrm{nM}\left[{ }^{3} \mathrm{H}\right]$ retinoic acid alone $(\bullet)$ or with $50 \mathrm{nM}\left[{ }^{3} \mathrm{H}\right] \mathrm{retinoic}$ acid plus a 200 fold excess of unlabeled retinoic acid $(\mathrm{O})$. The numbers on the abscissa represent equal fractions of gradient, with the smaller numbers representing the bottom of the gradient. The migration peaks of bovine serum albumin (BSA) (4.6S) and cytochrome-c (CYT-C) (1.71S) are indicated by arrows.

ity to differentiate during exposure to retinoic acid (28). The HL-60 cell line differentiates in the presence of retinoic acid, but we were not able to detect a cRABP. Taken together, the data from human leukemia cell studies suggest that $\mathrm{CRABP}$ is not universally required for the induction of differentiation or the inhibition of clonal growth. It is possible that the cells possess very low levels of cRABP that the present assay is not sensitive enough to detect. However, other mechanisms to explain biological activities of retinoic acid should be considered. For example, De Luca et al. (29) have proposed that retinoic acid may act on cells by altering glycosylation of membrane glycoproteins.

The data reported here suggest that retinoic acid could play a role in treatment of human myeloid leukemia. 13-cis-retinoic acid is given systemically to patients with dermatologic diseases with few side ef- fects (30-32). Retinoic acid serum levels of 0.3-0.5 $\mu \mathrm{g} / \mathrm{ml}(\sim 1 \mu \mathrm{M})$ are attainable (33). Also, the ability of retinoic acid to enhance normal granulopoiesis may be of additional benefit. In addition, the KG-1 cell line may provide a useful model for the study of the mechanism of inhibitory action of retinoids on human leukemic cells and provide a convenient assay system for examining the inhibitory effect of newly synthesized retinoids.

\section{ACKNOWLEDGMENTS}

We thank Dr. D. W. Golde for providing the Mo line-conditioned medium, Dr. J. L. Fahey for the K562 line, and Dr. S. Collins and Dr. R. Gallo for the HL-60 cell line. We thank Dr. Beverly Pawson and Dr. Scott from Hoffmann-La Roche, Inc., Nutley, N. J., for providing the 13-cis-retinoic acid and the $\left[{ }^{3} \mathrm{H}\right] \mathrm{retinoic}$ acid. We would also like to thank R. Simon and A. Holland for helping in the preparation of this manuscript. 
This work was supported in part by U. S. Public Health Service grants CA26038 and 16042 and by the Esther Smith and Bruce Fowler, Jr., Memorial Funds.

\section{REFERENCES}

1. Wolbach, S. B., and P. R. Howe. 1925. Tissue changes following deprivation of fat-soluble A vitamin. J. Exp. Med. 42: 753-777.

2. Sporn, M. B., N. M. Dunlop, D. L. Newton, and J. M. Smith. 1976. Prevention of chemical carcinogenesis by vitamin $A$ and its synthetic analogs (retinoids). Fed. Proc. 35: 1332-1338.

3. Moon, R. C., C. J. Grubbs, M. B. Sporn, and D. G. Goodman. 1977. Retinyl acetate inhibits mammary carcinogenesis induced by $N$-methyl- $N$-nitrosourea. Nature (Lond.). 267: 620-621.

4. Harisiadis, L., R. C. Miller, E. J. Hall, and C. Borek. 1978. A vitamin A analogue inhibits radiation-induced oncogenic transformation. Nature (Lond.). 274: 486487.

5. Merriman, R. L., and J. S. Bertram. 1979. Reversible inhibition by retinoids of 3-methylcholanthrene-induced neoplastic transformation in $\mathrm{C} 3 \mathrm{H} / 10 \mathrm{~T}^{1 / 2}$ clone 8 cells. Cancer Res. 39: 1661-1666.

6. Lotan, R. 1980. Effects of vitamin A and its analogs (retinoids) on normal and neoplastic cells. Biochim. Biophys. Acta. 605: 33-91.

7. Lotan, R., and G. L. Nicolson. 1977. Inhibitory effects of retinoic acid or retinyl acetate on the growth of untransformed, transformed and tumor cells in vitro. $J$. Natl. Cancer Inst. 59: 1717-1722.

8. Jetten, A. M., M. E. R. Jetten, S. S. Shapiro, and J. P. Poon. 1979. Characterization of the action of retinoids on mouse fibroblast cell lines. Exp. Cell Res. 119: 289299.

9. Lacroix, A., and M. E. Lippman. 1980. Binding of retinoids to human breast cancer cell lines and their effects on cell growth. J. Clin. Invest. 65: 586-591.

10. Strickland, S., and V. Mahdavi. 1978. The induction of differentiation in teratocarcinoma stem cells by retinoic acid. Cell. 15: 393-403.

11. Douer, D., and H. P. Koeffler. Retinoic acid enhances colony-stimulating factor induced clonal growth of normal human myeloid progenitor cells in vitro. Exp. Cell Res. In press.

12. Breitman, T. R., S. E. Selonick, and S. J. Collins. 1980. Induction of differentiation of the human promyelocytic leukemia cell line (HL-60) by retinoic acid. Proc. Natl. Acad. Sci. U. S. A. 77: 2936-2940.

13. Breitman, T. R., S. J. Collins, and B. R. Keene. 1981. Terminal differentiation of human promyelocytic leukemic cells in primary culture in response to retinoic acid. Blood. 57: 1000-1004.

14. Sachs, L. 1978. Control of normal cell differentiation and the phenotypic reversion of malignancy in myeloid leukemia. Nature (Lond.).274: 535-539.

15. Koeffler, H. P., and D. W. Golde. 1980. Human myeloid leukemia cell lines: a review. Blood. 56: 344-350.

16. Koeffler, H. P., and D. W. Golde. 1978. Acute myelog- enous leukemia: a human cell line responsive to colonystimulating activity. Science (Wash. D. C.). 200: 11531154.

17. Collins, S. J., R. C. Gallo, and R. E. Gallagher. 1977. Continuous growth and differentiation of human myeloid leukemic cells in suspension culture. Nature (Lond.). 270: 347-349.

18. Lozzio, C. B., and B. B. Lozzio. 1975. Human chronic myelogenous leukemia cell line with positive Philadelphia chromosome. Blood. 45: 321-334.

19. Ichikawa, Y. 1969. Differentiation of a cell line of myeloid leukemia. J. Cell. Physiol. 74: 223-234.

20. Gralnick, H. R., D. A. G. Galton, D. Catovsky, C. Sultan, and J. M. Bennet. 1977. Classification of acute leukemia. Ann. Intern. Med. 87: 740-753.

21. Golde, D. W., S. G. Quan, and M. J. Cline. 1978. Human T-lymphocyte cell line producing colony stimulating activity. Blood. 52: 1068-1072.

22. Ong, D. E., and F. Chytil. 1975. Retinoic acid binding protein in rat tissue. J. Biol. Chem. 250: 6113-6117.

23. Duttera, M. J., J. Whang-Peng, J. M. C. Bull, and P. P. Carbone. 1972. Cytogenetically abnormal cells in vitro in acute leukemia. Lancet. I: 715-717.

24. Ong, D. E., D. L. Page, and F. Chytil. 1975. Retinoic acid binding protein: occurrence in human tumors. Science (Wash. D. C.). 190: 60-61.

25. Jetten, A. M., and M. E. R. Jetten. 1979. Possible role of retinoic acid binding protein in retinoid stimulation of embryonal carcinoma cell differentiation. Nature (Lond.). 278: 180-182.

26. Lotan, R., G. Neumann, and D. Lotan. 1980. Relationship among retinoid structure, inhibition of growth and cellular retinoic acid-binding protein in cultured $\$ 91$ melonoma cells. Cancer Res. 40: 1097-1102.

27. Lotan, R., D. E. Ong, and F. Chytil. 1980. Comparison of the level of cellular retinoid-binding proteins and susceptibility to retinoid-induced growth inhibition of various neoplastic cell lines. J. Natl. Cancer Inst. 64: 12591262.

28. Schindler, J., K. I. Matthaei, and M. I. Sherman. 1981. Isolation and characterization of mouse mutant embryonal carcinoma cells which fail to differentiate in response to retinoic acid. Proc. Natl. Acad. Sci. U. S. A. 78: 1077-1080.

29. De Luca, L. M., J. P. Frot-Coutaz, C. S. Silverman-Jones, and P. R. Roller. 1977. Chemical synthesis of phosphorylated retinoids: their mannosyl acceptor activity in rat liver membranes. J. Biol. Chem. 252: 2575-2579.

30. Peck, G. L., T. G. Olsen, F. W. Yoder, J. S. Strauss, D. T. Downing, M. Pandya, D. Butkus, and J. ArnaudBattandier. 1979. Prolonged remissions of cystic and conglobate acne with 13-cis-retinoic acid. N. Engl. J. Med. 300: 329-333.

31. Jones, H., D. Blanc, and W. J. Cunliffe. 1980. 13-cisretinoic acid and acne. Lancet. II: 1048-1049.

32. Editorial. 1981. Retinoids in dermatology. Lancet. I: 537-538.

33. Frolik, C. A., T. E. Tavela, G. L. Peck, and M. B. Sporn. 1978. High-pressure liquid chromatographic determination of 13-cis retinoic acid and all-trans retinoic acid in human plasma. Anal. Biochem. 86: 743-750. 